\title{
Comparative efficacy of pharmacological agents on reducing the risk of major adverse cardiovascular events in the hypertriglyceridemia population: a network meta-analysis
}

Yan-yan Qi ${ }^{1}$, Li Yan ${ }^{2}$, Zhong-min Wang ${ }^{1}$, Xi Wang ${ }^{1}$, Hua Meng ${ }^{1}$, Wen-bo Li ${ }^{1}$, Dong-chang Chen ${ }^{1}$, Meng Li ${ }^{1}$, Jun Liu' and Song-tao $\mathrm{An}^{1 *}$

\begin{abstract}
Background: Hypertriglyceridemia (HTG) is considered an independent risk factor for major adverse cardiovascular events (MACE).

Methods: This study analyzed the effects of various agents on MACE risk reduction in HTG (serum triglyceride $\geq 150 \mathrm{mg} / \mathrm{dl}$ ) populations by performing a network meta-analysis. We performed a frequentist network metaanalysis to conduct direct and indirect comparisons of interventions. PubMed, EMBASE, and the Cochrane library were searched for trials until Jul 6, 2020. Randomized controlled trials that reported MACE associated with agents in entire HTG populations or in subgroups were included. The primary outcome was MACE.

Results: Of the 2005 articles screened, 21 trials including 56,471 patients were included in the analysis. The network meta-analysis results for MACE risk based on frequency data showed that eicosapentaenoic acid (EPA) (OR: 1.32; 95\% Cl 1.19-1.46), gemfibrozil (OR: 1.53; 95\% Cl 1.20-1.95), niacin plus clofibrate (OR: 2.00; 95\% Cl 1.23-3.25), pravastatin (OR: 1.32; 95\% Cl 1.15-1.52), simvastatin (OR: 2.38; 95\% Cl 1.55-3.66), and atorvastatin (OR: 0.55; 95\% Cl 0.37-0.82) significantly reduced the risk of MACE compared to the control conditions. In the subgroup analysis of HTG patients with triglycerides $\geq 200 \mathrm{mg} / \mathrm{dL}$, bezafibrate (OR: 0.56; 95\% Cl 0.33-0.94), EPA (OR: 0.72; 95\% Cl 0.62-0.82), and pravastatin (OR: $1.33 ; 95 \% \mathrm{Cl} 1.01-1.75)$ significantly reduced the MACE risk.
\end{abstract}

Conclusions: Simvastatin had a clear advantage in reducing the risk of MACE in the entire HTG population analyzed in this meta-analysis. EPA, but not omega-3 fatty acid, was considered an effective HTG intervention. Among fibrates, gemfibrozil was most effective, though bezafibrate may significantly reduce the risk of MACE in populations with triglyceride levels of $200-300 \mathrm{mg} / \mathrm{dL}$.

Trial registration retrospectively registered in PROSPERO (CRD42020213705).

Keywords: Hypertriglyceridemia, Major adverse cardiovascular events, Meta-analysis

*Correspondence: ansongtao907@126.com

1 Department of Cardiology, People's Hospital of Zhengzhou University No, 7, Weiwu Road, Zhengzhou 450003, China

Full list of author information is available at the end of the article

\section{Background}

Hypertriglyceridemia (HTG), a condition in which triglyceride levels are elevated (>150 $\mathrm{mg} / \mathrm{dl}[1.69 \mathrm{mmol} / \mathrm{L}])$, is considered an independent risk factor for major

c) The Author(s) 2021. This article is licensed under a Creative Commons Attribution 4.0 International License, which permits use, sharing, adaptation, distribution and reproduction in any medium or format, as long as you give appropriate credit to the original author(s) and the source, provide a link to the Creative Commons licence, and indicate if changes were made. The images or other third party material in this article are included in the article's Creative Commons licence, unless indicated otherwise in a credit line to the material. If material is not included in the article's Creative Commons licence and your intended use is not permitted by statutory regulation or exceeds the permitted use, you will need to obtain permission directly from the copyright holder. To view a copy of this licence, visit http://creativeco mmons.org/licenses/by/4.0/. The Creative Commons Public Domain Dedication waiver (http://creativecommons.org/publicdomain/ zero/1.0/) applies to the data made available in this article, unless otherwise stated in a credit line to the data. 
adverse cardiovascular events (MACE) [1, 2]. According to Task Force recommendations, people with mild or moderate HTG (triglycerides between $150 \mathrm{mg} / \mathrm{dl}$ [1.69 $\mathrm{mmol} / \mathrm{L}]$ and $999 \mathrm{mg} / \mathrm{dl}[11.3 \mathrm{mmol} / \mathrm{L}]$ ) have an increased risk of cardiovascular disease, and people with severe HTG (triglycerides of $>1000 \mathrm{mg} / \mathrm{dl}[11.3 \mathrm{mmol} / \mathrm{L}]$ ) have an increased risk of acute pancreatitis [3-5]. Realworld data based on the CANHEART cohort showed that HTG was very common in the atherosclerotic cardiovascular disease population, and elevated triglycerides (TGs) increased the risk of arteriosclerotic cardiovascular diseases (ASCVDs) [6].

Serum TGs are the main components of chylomicrons and very low-density lipoproteins (VLDLs) [7, 8]. VLDLs and chylomicrons can permeate the arterial intima and selectively deposit, eventually causing the accumulation of cholesterol in the arterial intima and plaque formation [9]. In addition, elevated TGs have an important effect on coagulation and fibrinolysis, inhibiting fibrinolysis, increasing blood viscosity, and promoting thrombosis [10]. Therefore, HTG has a direct effect on atherosclerosis, increasing the risk of major cardiovascular events [11]. For mild to moderate HTG $(177 \mathrm{mg} / \mathrm{dl}[2.0 \mathrm{mmol} / \mathrm{L}]$ to $885 \mathrm{mg} / \mathrm{dl}[10.0 \mathrm{mmol} / \mathrm{L}]$ ), statins are considered the first-line drug. Although statins reduce low-density lipoprotein cholesterol (LDL-C) to a greater extent than they reduce TGs, a small reduction in TGs may further reduce the residual risk of cardiovascular disease, which indicates the cardiovascular risk among statin-treated individuals $[12,13]$. In addition to statins, lifestyle modifications, such as cessation of alcohol consumption, reduced intake of rapidly metabolized carbohydrates, weight loss, and blood sugar control are highly effective ways to lower TG levels [14]. For many HTG patients, a further reduction in TGs may reduce the risk of residual cardiovascular disease [15]. Therefore, guidelines recommend fibrates, niacin, and omega- 3 fatty acids if HTG persists despite the application of high-intensity statin therapy [14]

A previous meta-analysis showed that marine omega-3 fatty acids, especially high eicosapentaenoic acid (EPA)content agents, have obvious TG-lowering effects; moreover, TG reduction was associated with major vascular event risk reduction [16]. Omega-3 fatty acids are generally well tolerated [17]. In a study of a human immunodeficiency virus (HIV)/acquired immunodeficiency syndrome (AIDS) population with HTG, the intake of EPA and docosahexaenoic acid (DHA) significantly reduced the risk of coronary heart disease (CHD) $[18,19]$. It is believed that fibrates can reduce the risk of cardiovascular disease in high-risk cardiovascular disease populations, such as patients with HTG or with atherogenic dyslipidemia (triglycerides $>150 \mathrm{mg}$ / dl $[1.69 \mathrm{mmol} / \mathrm{l}]$ and high density lipoprotein cholesterol $<40 \mathrm{mg} / \mathrm{dl}[1.03 \mathrm{mmol} / \mathrm{l}]$ in $\mathrm{men}$ or $<50 \mathrm{mg} / \mathrm{dl}$ [1.29 mmol/l] in women)[20-22].

Currently, studies on the effects of various drugs on MACE outcomes in HTG populations are still insufficient; in many studies, HTG populations have been analyzed separately from major cardiovascular disease risk populations in only subgroup or post hoc analyses. This study will analyze the effects of various agents on reducing the MACE risk in HTG populations by a network meta-analysis to identify efficacious agents for clinical application.

\section{Methods}

This network meta-analysis of published randomized controlled trials (RCTs) was performed according to the Preferred Reporting Items for Systematic Reviews and Meta-analyses incorporating Network Meta-Analyses (PRISMA-NMA) statement.

\section{Data sources, search strategy and selection criteria}

Data from relevant studies were obtained by searching the PubMed, EMBASE, and Cochrane library databases without language restrictions. No initial date restriction was applied, and the search end date was Jul 6, 2020. Keywords included "hypertriglyceridemia", "high triglyceride", "high triacylglycerols", "high triacylglycerides", "survival", "survivors", "death", "die", "mortality", "cardiovascular", "MACE", "random", "randomized", and "randomized". The search strategy details were list in Additional file 1: Table S1. Reference lists from identified trials and reviews were manually screened to identify additional trials.

\section{Inclusion and exclusion criteria}

The inclusion criteria included the following: 1 , a RCT design; 2, the inclusion of an HTG population; 3 a separate analysis of the HTG population in subgroup or post hoc analyses; and 3, the reporting of MACE-related outcomes. The exclusion criteria included the following: 1, studies without the inclusion of an HTG population; 2, studies that did not report the HTG population separately; 3 , dosage-related studies; 4 , lifestyle behavior or nursing-related intervention studies; or 5, studies that did not report MACE-related outcomes. Additionally, studies reporting zero MACE events in both groups were excluded because of small sample sizes or short followup periods. Conference summaries, editorial comments, and comments were also excluded.

\section{Data extraction and study quality assessment}

Two authors independently extracted relevant information from the included studies. The extracted content 
included the name of the first author or collaborative organization, publication time, sample size, average age of the population, study abbreviations, intervention and control agents, outcome assessment, and follow-up period. MACE outcomes mainly included sudden cardiac death (defined as the unexpected death of an individual not attributable to an extracardiac cause, usually within one hour of symptom onset; it's a consequence of many cardiovascular conditions, and the leading cause of SCD is coronary heart disease (CHD), which accounts for over $70 \%$ of SCD cases) [23, 24], fatal/nonfatal myocardial infarction (defined as a condition where there is interruption of blood supply to a part of the heart that led to a fatal or severe nonfatal event), and nonfatal stroke (defined as non-convulsive loss of neurological function due to brain ischemia or intracranial hemorrhages that led to a fatal or severe nonfatal event). Individual study definitions were used for the outcome analysis (see Additional file 2: Table S2 for details). The potential risk of bias of the included RCTs was evaluated using the risk assessment tool recommended by the Cochrane Collaboration guidelines (assessing random sequence generation; allocation concealment; blinding of participants and personnel; blinding of outcome assessment; incomplete outcome data; selective reporting; and other risk) [25].

\section{Statistical analysis}

Dichotomous data were combined to produce odds ratios (ORs), and 95\% confidence intervals (CIs). Hazard ratios (HRs) and 95\% CIs for Cox regression results were also calculated if raw event frequency data was not reported. A frequentist framework network meta-analysis was performed for mixed multiple treatment comparisons that combined direct and indirect evidence to obtain effect size [26]. Cochran's Q test was used to assess homogeneity in the whole network and the homogeneity/consistency between designs. The pairwise comparison results based on the network meta-analysis were obtained, and the effective ranking of various agents was performed based on the P-score [27]. A comparison-adjusted funnel plot was used to assess funnel plot asymmetry for the network meta-analysis. A p value less than 0.05 was considered to indicate a significant difference. The analyses were performed using the "netmeta" package in $\mathrm{R}$ language (version 4.0.2).

\section{Results}

\section{Literature screening}

Through public database searching, 695 studies were obtained from PubMed, 1661 studies were obtained from EMBASE, and 654 studies were obtained from the Cochrane library. After removing duplications, 2005 studies were obtained. A total of 1838 trials were excluded by title and abstract screening. A total of 167 full-text articles were reviewed. Additional studies were excluded on the basis of the following: the studies did not report the HTG population in their entirety or separately (55); the studies did not report MACE-related outcomes or reported no events in either arm (31); the studies were duplicated (18); the studies were reviews (17); the studies were conference summaries (13); the studies had nonRCT designs (5); the studies evaluated lifestyle behavior or nursing interventions (4); the studies were protocols (2); and the studies were dosage-related studies (1). For included post hoc studies, the latest reported results were included in the analysis. Finally, a total of 21 articles including 56,471 HTG patients were included in the analysis (Fig. 1) [28-48].

Included studies were published from 1988 to 2019. In terms of sample size, with the exception of one study that included only 59 patients [42], the studies included more than 300 patients. The average age of the population was approximately 60 years old, except in one article in which the average age was approximately 80 years old [29]. The shortest follow-up period among the included studies was 1 year [42] (Table 1). In most studies, the most common MACE were cardiovascular death, nonfatal myocardial infarction (MI), nonfatal stroke, acute coronary syndrome, and coronary revascularization. However, there were studies that reported only death events [31, 34, 35, 42, 47] (Additional file 2: Table S2). Regarding the research quality assessment, only two articles did not state their blinding method [40, 47], and two articles performed only blinding of the assessors [29, 37]. The rest of the study designs were of high quality. Thus, the overall quality of included studies was relatively satisfactory (Fig. 2).

The studies with MACE frequency data were analyzed first. The interventions included atorvastatin, bezafibrate, EPA, ezetimibe, omega-3 fatty acid, fenofibrate, gemfibrozil, niacin, niacin plus clofibrate, niacin plus laropiprant, pravastatin, simvastatin, and control (Fig. 3, A). Due to the included trials comparing interventions and control directly head to head, as well as the $\mathrm{Q}$ test results $(p=0.744)$, this study used consistency fixed-effect models. In pairwise comparisons, compared to control, EPA (OR: 1.32; 95\% CI 1.19-1.46), gemfibrozil (OR: 1.53; 95\% CI 1.20-1.95), niacin plus clofibrate (OR: 2.00; 95\% CI $1.23-3.25$ ), pravastatin (OR: 1.32 ; 95\% CI $1.15-1.52$ ), and simvastatin (OR: 2.38 ; 95\% CI 1.55-3.66) could significantly reduce the risk of MACE. In addition, atorvastatin could also significantly reduce MACE risk compared to control (OR: 0.55; 95\% CI 0.37-0.82) (Table 2). In omega-3 fatty acid research, due to the smaller number of patients and zero-events in the intervention arm [42], the accuracy of the omega-3 fatty acid results was 


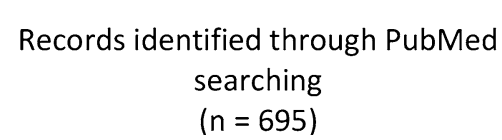

Additional records identified

through Embase $(n=1661)$ and

Cochrane library $(n=654)$
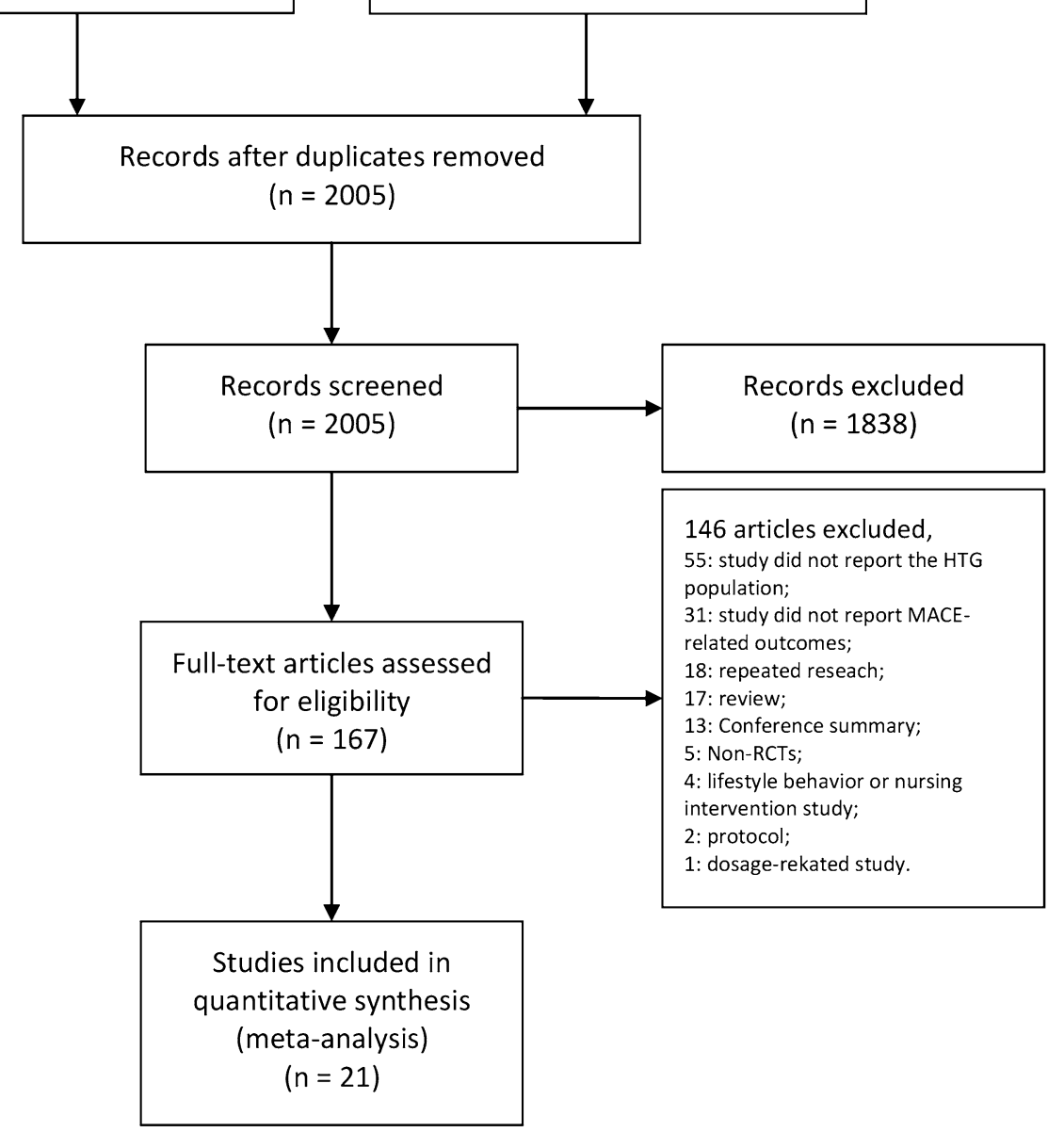

Fig. 1 Flow chart illustrating the study selection process of this meta-analysis

low with a wide $95 \%$ CI. P-score ranking results showed that simvastatin (0.899), niacin plus clofibrate (0.812), and atorvastatin (0.767) have relative advantages. A comparison-adjusted funnel plot showed no publication bias (Fig. 4a).

This study also conducted an analysis based on the HR results of the Cox regression analysis as a supplement to the results of the event frequency analysis because several studies did not report event frequency results but did report HR results [35, 36, 38]. The interventions included atorvastatin, EPA, ezetimibe, omega-3 fatty acids, fenofibrate, niacin, simvastatin and controls (Fig. 3b). A consistency fixed-effect model was used in the analysis ( $Q$ test: $p=0.133$ ). According to the pairwise results, EPA (HR: 1.12; 95\% CI 1.08-1.17), simvastatin (HR: 1.38; 95\% CI 1.17-1.61), and atorvastatin (HR: 0.90; 95\% CI 0.82-0.99) significantly reduced the MACE risk (Table 3). P-score ranking showed that simvastatin (0.979), ezetimibe (0.739), and EPA (0.690) had relative advantages. A comparison-adjusted funnel plot showed no publication bias (Fig. 4b).

We further classified the agents for analysis. The classifications included omega-3 fatty acids, fibrates, niacin, niacin plus fibrates, niacin plus laropiprant, selective cholesterol absorption inhibitors (SCAIs), and statins (Fig. 3c). Of these, statins are inhibitors of the hydroxymethylglutaryl-CoA (HMG-CoA) reductase enzyme to interfere with the endogenous synthesis of cholesterol. Ezetimibe inhibits the Niemann-Pick C1-Like 1 (NPC1L1) receptor to block intestinal cholesterol absorption. Omega-3 fatty acids are polyunsaturated fatty acids that regulate lipid metabolism by inhibiting lipogenesis and promoting lipolysis and are also involved in inflammatory regulation. Fibrates are a class of 
Table 1 The characteristics of included studies

\begin{tabular}{|c|c|c|c|c|c|c|c|c|c|}
\hline Author & Year & Local & Sample size & $\begin{array}{l}\text { Age\# } \\
\text { of intervention } \\
\text { group }\end{array}$ & $\begin{array}{l}\text { Age } \\
\text { of Control } \\
\text { group }\end{array}$ & Abbreviations & Intervention & Control & Follow-up \\
\hline Bhatt [28] & 2019 & Multination & 8179 & $64(57-69)$ & $64(57-69)$ & REDUCE-IT & EPA & Placebo & 4.9 Years \\
\hline Ouchi [29] & 2019 & Japan & 1046 & $80.6 \pm 4.7$ & $80.6 \pm 4.7$ & EWTOPIA 75 & Ezetimibe & Control & 5 Years \\
\hline Elam [30] & 2016 & US,Canada & 3635 & $62.3 \pm 6.8$ & $62.3 \pm 6.8$ & ACCORD & Fenofibrate & Placebo & 4.7 Years \\
\hline Arbel [31] & 2016 & Israel & 458 & $58 \pm 7$ & $58 \pm 7$ & $\mathrm{BIP}$ & Bezafibrate & Placebo & 20 Years \\
\hline Kalil [32] & 2015 & US & 3413 & $70.8 \pm 7.4$ & $70.6 \pm 7.2$ & AIM-HIGH & Niacin & Placebo & 4.1 Years \\
\hline Landray [33] & 2014 & UK,Scandinavia,China & 6575 & $64.9 \pm 7.5$ & $64.9 \pm 7.5$ & HPS2-THRIVE & $\begin{array}{l}\text { Niacin plus } \\
\text { laropiprant }\end{array}$ & Placebo & 3.9 Years \\
\hline Davidson [34] & 2014 & US & 676 & 61() & 61 (?) & FIRST & Fenofibrate & Placebo & 108 Weeks \\
\hline $\begin{array}{l}\text { The ORIGIN } \\
\text { Trial } \\
\text { Investigators } \\
\text { [35] }\end{array}$ & 2012 & Canada & 4270 & $63.5 \pm 7.8$ & $63.6 \pm 7.9$ & ORIGIN & $\begin{array}{l}\text { Omega-3 } \\
\text { fatty acid }\end{array}$ & Placebo & 6.2 Years \\
\hline $\begin{array}{c}\text { Amarenco } \\
{[36]}\end{array}$ & 2008 & Multinational & 1575 & $63.0 \pm 0.2$ & $62.5 \pm 0.2$ & SPARCL & Atorvastatin & Placebo & 4.9 Years \\
\hline $\begin{array}{l}\text { Yokoyama } \\
\text { [37] }\end{array}$ & 2007 & Japan & 9211 & $61 \pm 8$ & $61 \pm 9$ & JELIS & EPA & Control & 5 Years \\
\hline $\begin{array}{l}\text { The FIELD } \\
\text { study } \\
\text { investiga- } \\
\text { tors [38] }\end{array}$ & 2005 & Multinations & 5093 & $62.2 \pm 6.9$ & $62.2 \pm 6.8$ & FIELD & Fenofibrate & Placebo & 5 Years \\
\hline Colhoun [39] & 2004 & UK, Ireland & 1425 & $61.8 \pm 8.0$ & $61.5 \pm 8.3$ & CARDS & Atorvastatin & Placebo & 4 Years \\
\hline Sasaki [40] & 2002 & Japan & 497 & $55.5 \pm 10.2$ & $55.5 \pm 10.1$ & NA & Pravastatin & Control & 5 Years \\
\hline $\begin{array}{l}\text { Ballantyne } \\
\text { [41] }\end{array}$ & 2001 & Multinations & 458 & $57.7 \pm 7.8$ & $57.7 \pm 7.8$ & $4 S$ & Simvastatin & Placebo & 5.4 Years \\
\hline $\begin{array}{l}\text { Durrington } \\
\text { [42] }\end{array}$ & 2000 & UK & 59 & $55.2 \pm 7.0$ & $54.8 \pm 10.2$ & NA & $\begin{array}{l}\text { Omega-3 } \\
\text { fatty acid }\end{array}$ & Placebo & 1 Year \\
\hline Rubins [43] & 1999 & US & 1185 & $64 \pm 7$ & $64 \pm 7$ & VA-HIT & Gemfibrozil & Placebo & 5.1 Years \\
\hline Tonkin [44] & 1998 & $\begin{array}{l}\text { Australia, New } \\
\text { Zealand }\end{array}$ & 1490 & $62(55-67)$ & $62(55-68)$ & LIPID & Pravastatin & Placebo & 6.1 Years \\
\hline Sacks [45] & 1996 & US, Canada & 2079 & $59 \pm 9$ & $59 \pm 9$ & CARE & Pravastatin & Placebo & 5 Years \\
\hline $\begin{array}{l}\text { Shepherd } \\
{[46]}\end{array}$ & 1995 & UK & 3356 & $55.3 \pm 5.5$ & $55.1 \pm 5.5$ & WSCPS & Pravastatin & Placebo & 4.9 Years \\
\hline Carlson [47] & 1988 & Sweden & 301 & $\begin{array}{l}\text { Males } 59.2 \pm 0.4 \\
\text { Female } \\
\quad 63.0 \pm 0.7\end{array}$ & $\begin{array}{l}\text { Male } \\
58.9 \pm 0.4 \\
\text { Females } \\
62.5 \pm 0.9\end{array}$ & SIHDSPS & $\begin{array}{l}\text { Niacin plus } \\
\text { Clofibrate }\end{array}$ & Control & 5 Years \\
\hline $\begin{array}{l}\text { Manninen } \\
\text { [48] }\end{array}$ & 1988 & Finland & 1490 & NA (40-55) & NA (40-55) & $\mathrm{HHS}$ & Gemfibrozil & Placebo & 5 Years \\
\hline
\end{tabular}

NA not available, EPA eicosapentaenoic acid. The full name of abbreviation for each study and the detail of major adverse cardiovascular events assessment were list in Additional file 2: Table S2

\# Average age showed as: Mean \pm Standard deviation or median (minimum-maximum)

(See figure on next page.)

Fig. 2 Risk of bias of each included study

phenoxyisobutyric acid derivatives and serve as agonists for the peroxisome proliferator-activated receptor alpha (PPAR alpha) to limit triglyceride synthesis and promote lipoprotein lipase. Niacin binds with $G$ protein-coupled receptor (GPR) 109A to reduce triglycerides and increase HDL-C. For this analysis, a consistency fixed-effect model was adopted ( $\mathrm{Q}$ test: $\mathrm{p}=0.098)$. According to the pairwise comparisons, omega-3 fatty acids (OR: 1.32; 95\% CI 1.19-1.46), fibrates (OR: 1.21; 95\% CI 1.05-1.40), niacin plus fibrates (OR: 2.00; 95\% CI 1.23-3.25), and statins (OR: 1.44; 95\% CI 1.27-1.63) significantly reduced the MACE risk compared to controls (Tables 4 and 5). A comparison-adjusted funnel plot showed no obvious publication bias (Fig. 4c). 


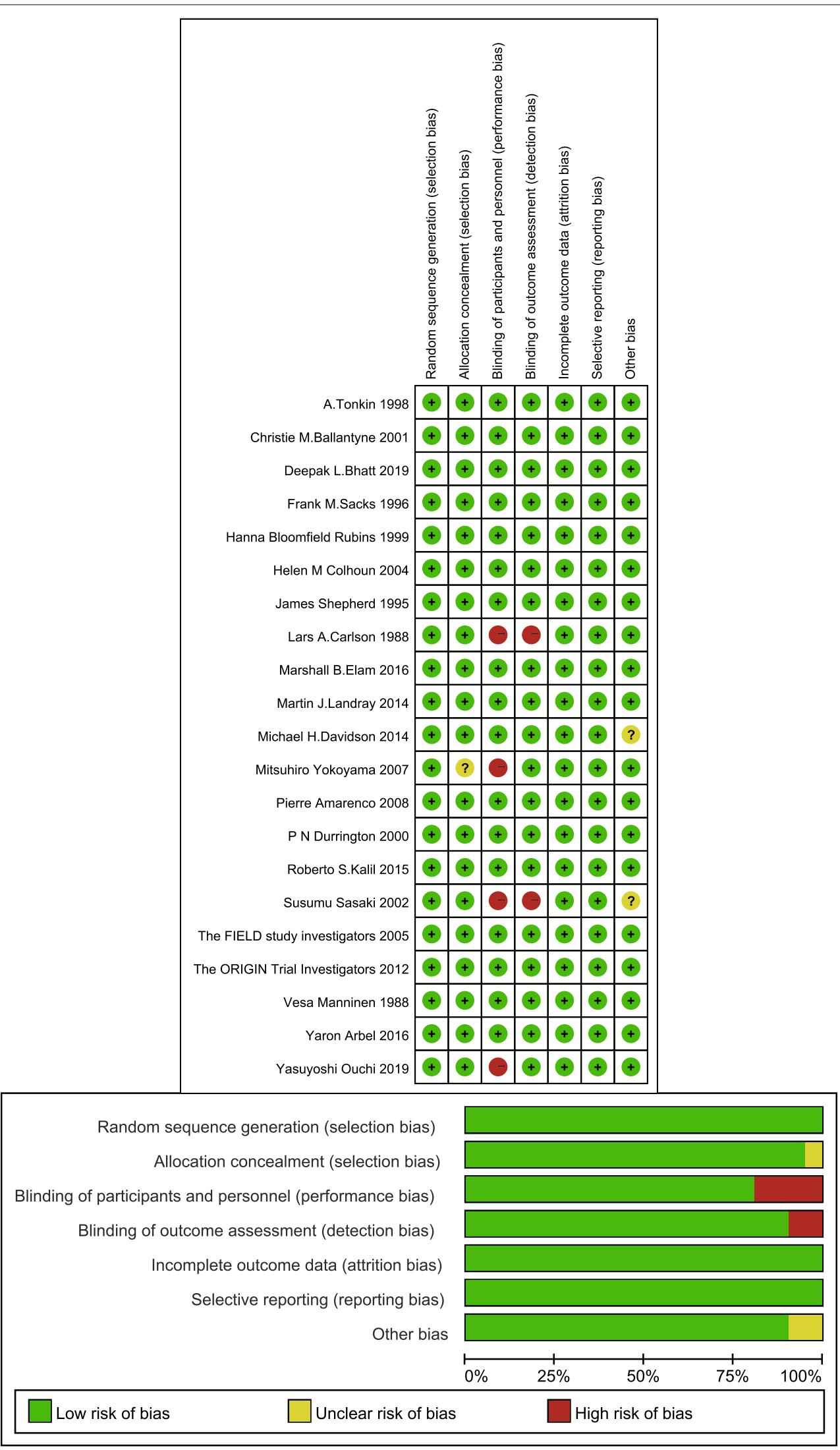




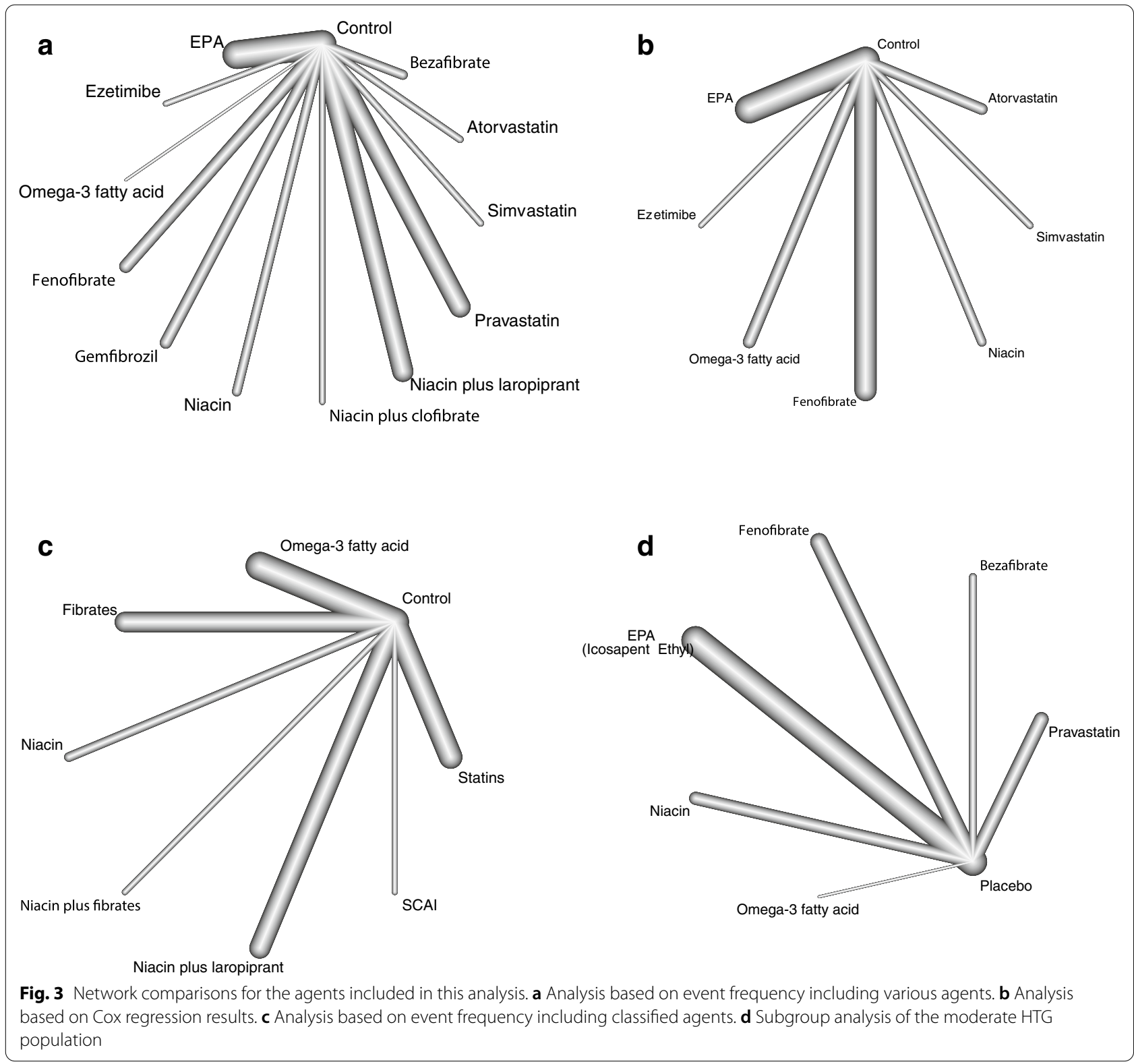

Because of the different criteria for HTG diagnosis and interest in the treatment of moderate HTG patients, we performed a subgroup analysis of HTG patients with $\mathrm{TGs} \geq 200 \mathrm{mg} / \mathrm{dl} \quad(2.38 \mathrm{mmol} / \mathrm{L})$. The interventions included EPA, fenofibrate, bezafibrate, niacin, omega-3 fatty acid, and pravastatin. The pairwise comparisons showed that bezafibrate (OR: 0.56; 95\% CI 0.33-0.94), EPA (OR: 0.72; 95\% CI 0.62-0.82), and pravastatin (OR: 1.33; 95\% CI 1.01-1.75) significantly reduced the MACE risk. P-score ranking showed that bezafibrate (0.823), omega-3 fatty acid (0.715), and EPA (0.675) have relative advantages. No obvious asymmetry was found in the comparison-adjusted funnel plot.

\section{Discussion}

TG level was an independent risk factor for cardiovascular events, despite adjustment for the LDL-C level [49]. Currently, there is a lack of meta-analyses of the effects of various agents on the MACE risk reduction in the HTG population. This study analyzed this topic by network meta-analysis. Statins, niacin, fibrates, omega-3 fatty acids, and ezetimibe were included in the analysis. It was found that simvastatin is superior to other agents for MACE risk reduction, and niacin plus clofibrate, EPA, and gemfibrozil also have relative advantages. The subgroup analysis of the population 


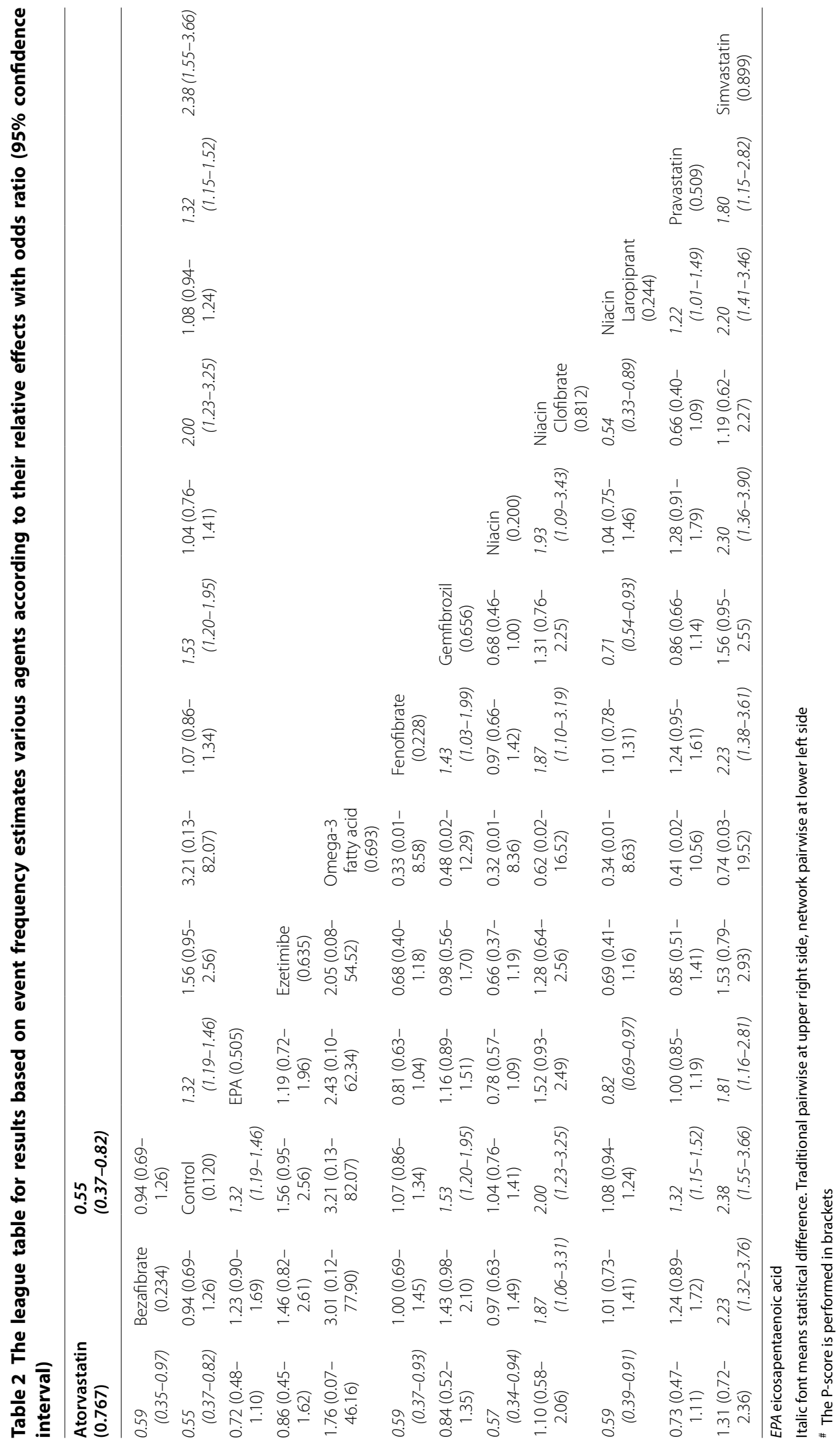



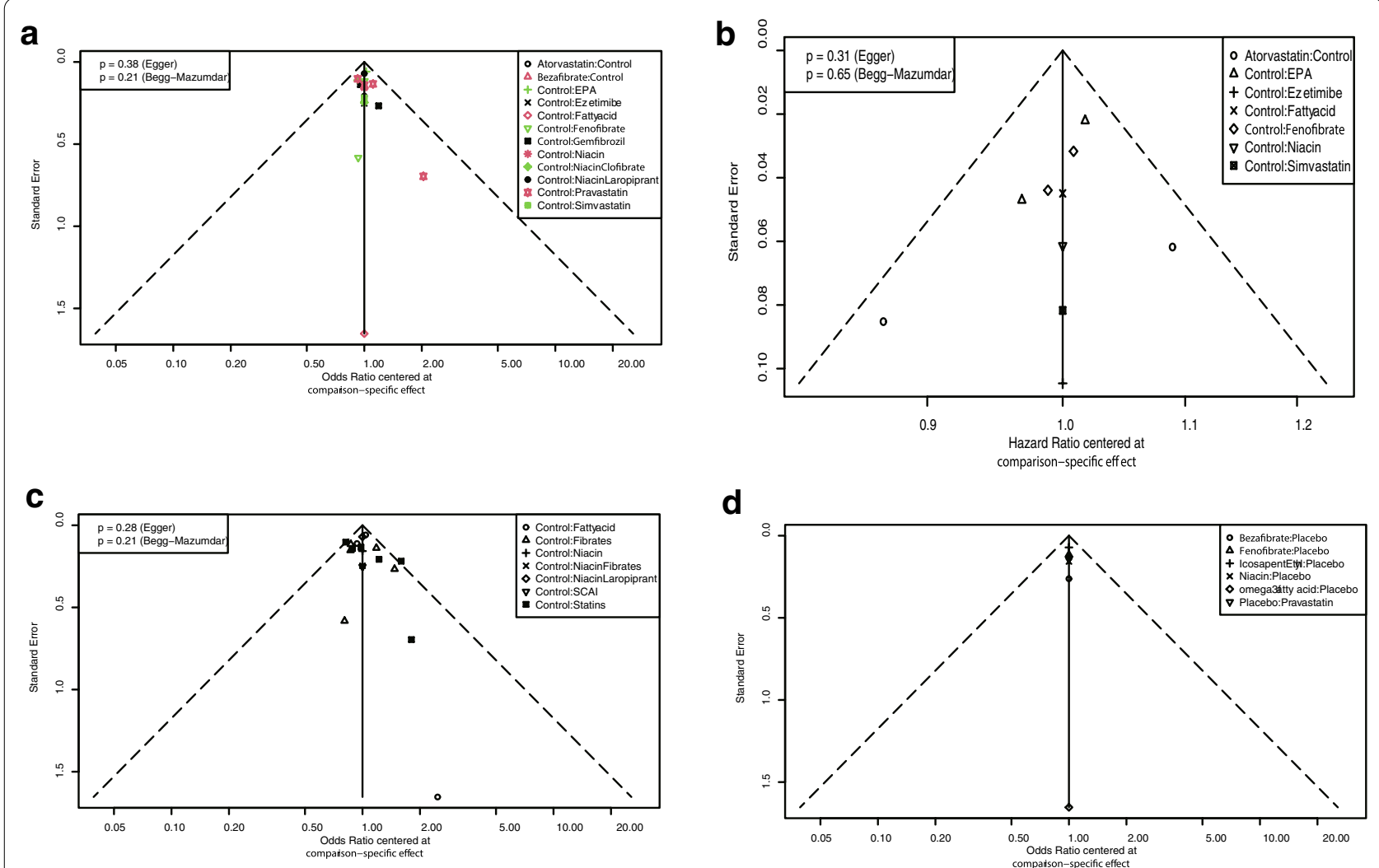

Fig. 4 Comparison-adjusted funnel plot for assessing potential publication bias. a Analysis based on event frequency including various agents. b Analysis based on Cox regression results. c Analysis based on event frequency including classified agents. $\mathbf{d}$ Subgroup analysis of the moderate HTG population

Table 3 The league table for results based on Cox-regression estimates various agents according to their relative effects with hazard ratio $(95 \%$ confidence interval)

\begin{tabular}{|c|c|c|c|c|c|c|c|}
\hline Atorvastatin & $0.90(0.82-0.99)$ & & & & & & \\
\hline $0.90(0.82-0.99)$ & Control (0.159) & $1.12(1.08-1.17)$ & $1.18(0.96-1.45)$ & $0.99(0.90-1.08)$ & $1.05(0.99-1.10)$ & $1.02(0.90-1.15)$ & $1.38(1.17-1.61)$ \\
\hline $1.01(0.91-1.12)$ & $1.12(1.08-1.17)$ & EPA (0.690) & & & & & \\
\hline $1.07(0.85-1.34)$ & $1.18(0.96-1.45)$ & $1.05(0.85-1.30)$ & Ezetimibe (0.739) & & & & \\
\hline $0.89(0.78-1.01)$ & $0.99(0.90-1.08)$ & $0.88(0.80-0.97)$ & $0.83(0.67-1.04)$ & $\begin{array}{l}\text { Omega-3 fatty } \\
\text { acid (0.138) }\end{array}$ & & & \\
\hline $0.94(0.84-1.05)$ & $1.05(0.99-1.10)$ & $0.93(0.87-0.99)$ & $0.88(0.72-1.09)$ & $1.06(0.96-1.17)$ & $\begin{array}{c}\text { Fenofibrate } \\
(0.395)\end{array}$ & & \\
\hline $0.92(0.79-1.07)$ & $1.02(0.90-1.15)$ & $0.91(0.80-1.03)$ & $0.86(0.68-1.09)$ & $1.03(0.89-1.20)$ & $0.97(0.85-1.11)$ & Niacin (0.275) & \\
\hline $1.24(1.03-1.50)$ & $1.38(1.17-1.61)$ & $1.22(1.04-1.44)$ & $1.16(0.90-1.51)$ & $1.39(1.16-1.67)$ & $1.32(1.11-1.56)$ & $1.35(1.11-1.65)$ & Simvastatin (0.979) \\
\hline
\end{tabular}

EPA eicosapentaenoic acid

Italic font means statistical difference. Traditional pairwise at upper right side, network pairwise at lower left side

\# The $\mathrm{P}$-score is performed in brackets

with TGs $\geq 200 \mathrm{mg} / \mathrm{dL}$ showed that bezafibrate and omega-3 fatty acids have relative advantages.

Niacin plus clofibrate has relative advantages in reducing the MACE risk in HTG patients based on a study published in 1988 [47]. Clofibrate is a fibric acid derivative used as a hypertriglyceridemia therapy [50]. However, clofibrate was withdrawn from the market in 2002 because of concern about its side effects, including elevated transaminase and rare acute liver injury [51]. In the analysis based on HR results, ezetimibe was found to 
Table 4 The league table for results based on event frequency estimates classified agents according to their relative effects with odds ratio ( $95 \%$ confidence interval)

\begin{tabular}{|c|c|c|c|c|c|c|c|}
\hline Control (0.084) & $1.32(1.19-1.46)$ & $1.21(1.05-1.40)$ & $1.04(0.76-1.41)$ & $2.00(1.23-3.25)$ & $1.08(0.94-1.24)$ & $1.56(0.95-2.56)$ & $1.44(1.27-1.63)$ \\
\hline $1.32(1.19-1.46)$ & $\begin{array}{l}\text { Omega-3 fatty } \\
\text { acid }(0.600)\end{array}$ & & & & & & \\
\hline $1.21(1.05-1.40)$ & $0.92(0.77-1.10)$ & Fibrates (0.444) & & & & & \\
\hline $1.04(0.76-1.41)$ & $0.78(0.57-1.08)$ & $0.85(0.61-1.20)$ & Niacin (0.194) & & & & \\
\hline $2.00(1.23-3.25)$ & $1.52(0.93-2.48)$ & $1.65(1.00-2.73)$ & $1.93(1.09-3.43)$ & $\begin{array}{l}\text { Niacin Fibrates } \\
(0.938)\end{array}$ & & & \\
\hline $1.08(0.94-1.24)$ & $0.82(0.69-0.97)$ & $0.89(0.73-1.09)$ & $1.04(0.75-1.46)$ & $0.54(0.33-0.89)$ & $\begin{array}{l}\text { NiacinLaropiprant } \\
(0.242)\end{array}$ & & \\
\hline $1.56(0.95-2.56)$ & $1.18(0.71-1.96)$ & $1.29(0.77-2.15)$ & $1.51(0.84-2.70)$ & $0.78(0.39-1.56)$ & $1.45(0.86-2.41)$ & SCAI (0.749) & \\
\hline $1.44(1.27-1.63)$ & $1.09(0.93-1.28)$ & $1.18(0.98-1.43)$ & $1.39(1.00-1.93)$ & $0.72(0.44-1.18)$ & $1.33(1.10-1.60)$ & $0.92(0.55-1.53)$ & Statins (0.749) \\
\hline
\end{tabular}

SCAl selective cholesterol absorption inhibitors

Italic font means statistical difference. Traditional pairwise at upper right side, network pairwise at lower left side

\# The P-score is performed in brackets

Table 5 The league table for results based on event frequency estimates agents for moderate HTG population according to their relative effects with odds ratio $(95 \%$ confidence interval)

\begin{tabular}{|c|c|c|c|c|c|c|}
\hline \multicolumn{5}{|l|}{ Bezafibrate (0.823) } & \multicolumn{2}{|l|}{$0.56(0.33-0.94)$} \\
\hline $0.60(0.34-1.05)$ & Fenofibrate (0.290) & & & & $0.93(0.74-1.17)$ & \\
\hline $0.78(0.46-1.33)$ & $1.30(1.00-1.70)$ & Icosapent Ethyl (0.675) & & & $0.72(0.62-0.82)$ & \\
\hline $0.58(0.32-1.05)$ & $0.97(0.66-1.41)$ & $0.74(0.53-1.04)$ & Niacin (0.244) & & $0.97(0.71-1.31)$ & \\
\hline $1.80(0.07-47.78)$ & $2.99(0.12-77.15)$ & $2.30(0.09-58.97)$ & $3.10(0.12-80.45)$ & $\begin{array}{l}\text { Omega-3 fatty acid } \\
\quad(0.715)\end{array}$ & $0.31(0.01-7.96)$ & \\
\hline $0.56(0.33-0.94)$ & $0.93(0.74-1.17)$ & $0.72(0.62-0.82)$ & $0.97(0.71-1.31)$ & $0.31(0.01-7.96)$ & Placebo (0.161) & $1.33(1.01-1.75)$ \\
\hline $0.74(0.41-1.33)$ & $1.24(0.86-1.77)$ & $0.95(0.70-1.29)$ & $1.28(0.85-1.94)$ & $0.41(0.02-10.68)$ & $1.33(1.01-1.75)$ & Pravastatin (0.593) \\
\hline
\end{tabular}

HTG hypertriglyceridemia

Italic font means statistical difference. Traditional pairwise at upper right side, network pairwise at lower left side

\# The P-score is performed in brackets

reduce the risk of MACE, but the results were not significant. In the original study, ezetimibe reduced the risk of cardiovascular events in people with elevated LDL-C and those $\geq 75$ years old. For those with LDL-C but without HTG, the effect of ezetimibe was obvious (HR: 0.65; 95\% CI $0.47-0.91 ; \mathrm{p}=0.011$ ) [29]. A systematic review also concluded that the combination of a statin and ezetimibe is more effective for lowering LDL-C levels than for lowering TG levels [52].

Two studies, the REDUCE-IT [28] and JELIS [37] studies, included EPA interventions. According to the results of these studies, EPA significantly reduced the risk of MACE compared to the control. However, omega-3 fatty acids showed no benefit in reducing the risk of MACE [35]. The results based on event frequency were also inaccurate due to zero events in the intervention arm [42]. However, it is generally believed that the effect of omega-3 fatty acids is inferior to that of EPA along, and DHA may cause an increase in LDL-C levels. This might be the reason why the Epanova (omega-3-carboxylic acids) study (NCT02104817) was discontinued; it had only limited benefits in mixed dyslipidemia patients [53]. In general, EPA is still considered an effective HTG treatment.

Fibrates including gemfibrozil, fenofibrate, and bezafibrate mainly act to clinically reduce TGs. Our results showed that gemfibrozil had a significant effect on reducing the risk of MACE compared with the control. However, its clinical application rate has gradually decreased, mainly due to muscle-related and blood-related side effects [54]. Therefore, gemfibrozil was mostly used for very high TG level intervention [55]. In the BIP study, bezafibrate was believed to be effective in those with TGs $\geq 200 \mathrm{mg} / \mathrm{dL}$ but not in those with TGs $\geq 150 \mathrm{mg} /$ $\mathrm{dL}$ in the multivariate analysis after adjusting for age, previous MI, use of non-study-related lipid-lowering medication, and diabetes mellitus [31]. It is possible that in moderate HTG patients, bezafibrate has good TG-lowering effects that further reduce the MACE 
risk. A post hoc study also showed that among patients with $\mathrm{TGs} \geq 200 \mathrm{mg} / \mathrm{dL}$, those whose TGs decreased by $>0.5 \mathrm{mmol} / \mathrm{L}$ after intervention attained a greater effect in reducing their MACE risk [56]. However, compared with those in other studies, the patients in the BIP study had a lower TG upper limit (TG $\leq 300 \mathrm{mg} / \mathrm{dL}$ ), so the benefit of bezafibrate in those with TGs $\geq 300 \mathrm{mg} /$ $\mathrm{dL}$ is still unclear. Furthermore, the value of fenofibrate might have been under-estimated by population selection. In dyslipidemic diabetic patients, fenofibrate may be effective in reducing MACE risk [30, 38]. Pemafibrate is also a novel, highly selective peroxisome proliferatoractivated receptor (PPAR)- $\alpha$ modulator (SPPARM) that can modulate lipid metabolism to decrease plasma triglyceride levels and increase high-density lipoprotein cholesterol levels[57, 58]. It has been approved in Japan for hyperlipidemia treatment [59]. However, MACE results for RCTs investigating pemafibrate were not completed at the initiation of this study, so pemafibrate was not analyzed in this work [60].

It should be noted that nonstatin intervention studies did not restrict the administration of statins in either arm. In some studies, all patients in both arms were treated with statins [32, 34]. Therefore, even if agents such as fibrates or EPA show benefits, the use of statins as first-line drugs will not change. Especially in comparisons with control groups, simvastatin showed obvious advantages.

In addition, familial hypertriglyceridemia (FHTG) is a familial autosomal dominant disease characterized by excessive triglyceride and VLDLs and is often found with polygenic genetic characteristics [61]. Due to insufficient investigation of the familial aggregation of HTG and the similar treatment strategy for reducing serum TG, there is still a lack of RCTs about FHTG. Thus, this work did not distinguish whether HTG in patients was familial or nonfamilial.

There were some limitations in this study. This study did not analyze the influence of patient characteristics and accompanying treatment on the results. Therefore, our study analyzed the effects of different agents in HTG populations. For patients with specific concomitant diseases, to account for accompanying treatment or type of dyslipidemia, more targeted studies are needed. In addition, this meta-analysis did not include studies analyzing lifestyle behavior interventions, although it is widely believed that good dietary and exercise habits are beneficial to TG reduction. Although the MACE criteria within individual studies were consistent, there were differences among the included studies. This study analyzed only the effects of various agents on reducing MACE risk in the HTG population, but side effects should be considered in clinical application when choosing personalized treatment regimens.

\section{Conclusions}

Overall, among the statins, simvastatin maintained a clear advantage in reducing the risk of MACE in the HTG population. EPA, but not omega-3 fatty acid, was considered an effective HTG intervention. Among the fibrates, gemfibrozil was most effective, and bezafibrate may significantly reduce the risk of MACE in populations with TG levels of $200-300 \mathrm{mg} / \mathrm{dL}$.

\section{Supplementary Information}

The online version contains supplementary material available at https://doi. org/10.1186/s13098-021-00626-7.

Additional file 1: Table S1. Search strategy in PubMed database.

Additional file 2: Table S2. The full names of the included studies and details of the MACE assessments.

\section{Abbreviations}

AIDS: Acquired immunodeficiency syndrome; ASCVDs: Arteriosclerotic cardiovascular diseases; CHD: Coronary heart disease; Cls: Confidence intervals; DHA: Docosahexaenoic acid; EPA: Eicosapentaenoic acid; HIV: Human immunodeficiency virus; HTG: Hypertriglyceridemia; HRs: Hazard ratios; LDL-C: Low-density lipoprotein cholesterol; MACE: Major adverse cardiovascular event; MI: Myocardial infarction; OR: Odds ratio; PRISMA-NMA: Preferred reporting items for systematic reviews and meta-analyses incorporating network meta-analyses; RCT: Randomized controlled trial; SCAI: Selective cholesterol absorption inhibitor; TG: Triglyceride; VLDL: Very low-density lipoprotein.

\section{Acknowledgements}

Not applicable.

\section{Authors' contributions}

$Y Q, L Y$, and SA performed study concepts and design, and wrote the manuscript. ZW and XW performed literature research. HM and WL collected data from included articles. DC, ML, and JL analyzed the data and prepared figures. All authors read and approved the final manuscript.

\section{Funding}

The present study was supported by National Natural Science Foundation of China (No. 81970312); Natural Science Foundation of Henan Province (No. 182300410304).

\section{Availability of data and materials}

All data generated or analysed during this study are included in this published article and its additional files.

\section{Ethics approval and consent to participate}

Not applicable.

\section{Consent for publication}

Not applicable.

Competing interests

The authors declare that they have no competing interests.

\section{Author details}

${ }^{1}$ Department of Cardiology, People's Hospital of Zhengzhou University No, 7, Weiwu Road, Zhengzhou 450003, China. ${ }^{2}$ Department of Cardiology, Hongxing hospital, Hami 839000, China. 
Received: 14 October 2020 Accepted: 6 January 2021

Published online: 29 January 2021

\section{References}

1. Nordestgaard BG, Varbo A. Triglycerides and cardiovascular disease. Lancet. 2014;384:626-35.

2. Kluge S, Boermel L, Schubert M, Lorkowski S. Simple and rapid real-time monitoring of LPL activity in vitro. MethodsX. 2020;7:100865.

3. Stroes ESG, Susekov AV, de Bruin TWA, Kvarnstrom M, Yang H, Davidson $\mathrm{MH}$. Omega-3 carboxylic acids in patients with severe hypertriglyceridemia: EVOLVE II, a randomized, placebo-controlled trial. J Clin Lipidol. 2018;12:321-30

4. Nurmohamed NS, Dallinga-Thie GM, Stroes ESG. Targeting apoC-III and ANGPTL3 in the treatment of hypertriglyceridemia. Exp Rev Cardiovasc Ther. 2020;18:355-61.

5. Berglund L, Brunzell JD, Goldberg AC, Goldberg IJ, Sacks F, Murad MH, et al. Evaluation and treatment of hypertriglyceridemia: an Endocrine Society clinical practice guideline. J Clin Endocrinol Metab. 2012;97:2969-89.

6. Lawler PR, Kotrri G, Koh M, Goodman SG, Farkouh ME, Lee DS, et al. Realworld risk of cardiovascular outcomes associated with hypertriglyceridaemia among individuals with atherosclerotic cardiovascular disease and potential eligibility for emerging therapies. Eur Heart J. 2020;41:86-94.

7. Sun CJ, McCudden C, Brisson D, Shaw J, Gaudet D, Ooi TC. Calculated non-HDL cholesterol includes cholesterol in larger triglyceride-rich lipoproteins in hypertriglyceridemia. J Endocr Soc. 2020;4:10.

8. Packard CJ, Boren J, Taskinen MR. Causes and consequences of hypertriglyceridemia. Front Endocrinol (Lausanne). 2020;11:252.

9. Janoudi A, Shamoun FE, Kalavakunta JK, Abela GS. Cholesterol crystal induced arterial inflammation and destabilization of atherosclerotic plaque. Eur Heart J. 2016;37:1959-67.

10. Reiner Z. Hypertriglyceridaemia and risk of coronary artery disease. Nat Rev Cardiol. 2017:14:401-11

11. Toth PP. Triglyceride-rich lipoproteins as a causal factor for cardiovascular disease. Vasc Health Risk Manag. 2016;12:171-83.

12. Karlson BW, Palmer MK, Nicholls SJ, Lundman P, Barter PJ. A VOYAGER meta-analysis of the impact of statin therapy on low-density lipoprotein cholesterol and triglyceride levels in patients with hypertriglyceridemia. Am J Cardiol. 2016;117:1444-8.

13. Mora S, Glynn RJ, Boekholdt SM, Nordestgaard BG, Kastelein JJ, Ridker PM On-treatment non-high-density lipoprotein cholesterol, apolipoprotein $B$, triglycerides, and lipid ratios in relation to residual vascular risk after treatment with potent statin therapy: JUPITER (justification for the use of statins in prevention: an intervention trial evaluating rosuvastatin). J Am Coll Cardiol. 2012;59:1521-8.

14. Kushner PA, Cobble ME. Hypertriglyceridemia: the importance of identifying patients at risk. Postgrad Med. 2016;128:848-58.

15. Patel PN, Patel SM, Bhatt DL. Cardiovascular risk reduction with icosapent ethyl. Curr Opin Cardiol. 2019;34:721-7.

16. Marston NA, Giugliano RP, Im K, Silverman MG, O'Donoghue ML, Wiviott $\mathrm{SD}$, et al. Association between triglyceride lowering and reduction of cardiovascular risk across multiple lipid-lowering therapeutic classes: a systematic review and meta-regression analysis of randomized controlled trials. Circulation. 2019;140:1308-17.

17. Ito MK. Long-chain omega-3 fatty acids, fibrates and niacin as therapeutic options in the treatment of hypertriglyceridemia: a review of the literature. Atherosclerosis. 2015;242:647-56

18. Alexander DD, Miller PE, Van Elswyk ME, Kuratko CN, Bylsma LC. A metaanalysis of randomized controlled trials and prospective cohort studies of eicosapentaenoic and docosahexaenoic long-chain omega-3 fatty acids and coronary heart disease risk. Mayo Clin Proc. 2017;92:15-29.

19. Vieira ADS, Silveira G. Effectiveness of $n-3$ fatty acids in the treatment of hypertriglyceridemia in HIV/AIDS patients: a meta-analysis. Cien Saude Colet. 2017:22:2659-69.

20. Bruckert E, Labreuche J, Deplanque D, Touboul PJ, Amarenco P. Fibrates effect on cardiovascular risk is greater in patients with high triglyceride levels or atherogenic dyslipidemia profile: a systematic review and metaanalysis. J Cardiovasc Pharmacol. 2011;57:267-72.
21. Jun M, Foote $C, L \vee$ J Neal B, Patel A, Nicholls SJ, et al. Effects of fibrates on cardiovascular outcomes: a systematic review and meta-analysis. Lancet. 2010;375:1875-84

22. Castaner O, Pinto X, Subirana I, Amor AJ, Ros E, Hernaez A, et al. Remnant cholesterol, not LDL cholesterol, is associated with incident cardiovascular disease. J Am Coll Cardiol. 2020;76:2712-24.

23. Fishman Gl, Chugh SS, Dimarco JP, Albert CM, Anderson ME, Bonow $\mathrm{RO}$, et al. Sudden cardiac death prediction and prevention: report from a National Heart, Lung, and Blood Institute and Heart Rhythm Society Workshop. Circulation. 2010;122:2335-48.

24. Wong CX, Brown A, Lau DH, Chugh SS, Albert CM, Kalman JM, et al. Epidemiology of sudden cardiac death: global and regional perspectives. Heart Lung Circ. 2019;28:6-14.

25. Cho Y, Kim C, Kang B. Risk of bias assessment of randomised controlled trials referenced in the 2015 American Heart Association guidelines update for cardiopulmonary resuscitation and emergency cardiovascular care: a cross-sectional review. BMJ Open. 2019;9:e023725.

26. Torbahn G, Hofmann H, Rucker G, Bischoff K, Freitag MH, Dersch R, et al Efficacy and safety of antibiotic therapy in early cutaneous Lyme Borreliosis: a network meta-analysis. JAMA Dermatol. 2018;154:1292-303.

27. Johnston BW, Hill R, Duarte R, Chean CS, McAuley DF, Blackwood B, et al. Protocol for a systematic review and network meta-analysis of the management of new onset atrial fibrillation in critically unwell adult patients. Syst Rev. 2019;8:242.

28. Bhatt DL, Steg PG, Miller M, Brinton EA, Jacobson TA, Ketchum SB, et al. Cardiovascular risk reduction with icosapent ethyl for hypertriglyceridemia. N Engl J Med. 2019:380:11-22.

29. Ouchi Y, Sasaki J, Arai H, Yokote K, Harada K, Katayama Y, et al. Ezetimibe lipid-lowering trial on prevention of atherosclerotic cardiovascular disease in 75 or older (EWTOPIA 75): a randomized. Controll Trial Circ. 2019:140:992-1003.

30. Elam MB, Ginsberg HN, Lovato LC, Corson M, Largay J, Leiter LA, et al. Association of fenofibrate therapy with long-term cardiovascular risk in statin-treated patients with type 2 diabetes. JAMA Cardiol. 2017;2:370-80.

31. Arbel Y, Klempfner R, Erez A, Goldenberg I, Benzekry S, Shlomo N, et al. Bezafibrate for the treatment of dyslipidemia in patients with coronary artery disease: 20-year mortality follow-up of the BIP randomized control trial. Cardiovasc Diabetol. 2016:15:11.

32. Kalil RS, Wang JH, de Boer $I H$, Mathew $R O$, Ix JH, Asif A, et al. Effect of extended-release niacin on cardiovascular events and kidney function in chronic kidney disease: a post hoc analysis of the AIM-HIGH trial. Kidney Int. 2015:87:1250-7.

33. Group HTC, Landray MJ, Haynes R, Hopewell JC, Parish S, Aung T, et al. Effects of extended-release niacin with laropiprant in high-risk patients. N Engl J Med. 2014;371:203-12.

34. Davidson MH, Rosenson RS, Maki KC, Nicholls SJ, Ballantyne CM, Mazzone T, et al. Effects of fenofibric acid on carotid intima-media thickness in patients with mixed dyslipidemia on atorvastatin therapy: randomized, placebo-controlled study (FIRST). Arterioscler Thromb Vasc Biol. 2014;34:1298-306.

35. Investigators OT, Bosch J, Gerstein HC, Dagenais GR, Diaz R, Dyal L, et al. n-3 fatty acids and cardiovascular outcomes in patients with dysglycemia. N Engl J Med. 2012;367:309-18.

36. Amarenco P, Goldstein LB, Callahan A 3rd, Sillesen H, Hennerici MG, O'Neill BJ, et al. Baseline blood pressure, low- and high-density lipoproteins, and triglycerides and the risk of vascular events in the Stroke Prevention by Aggressive Reduction in Cholesterol Levels (SPARCL) trial. Atherosclerosis. 2009;204:515-20.

37. Yokoyama M, Origasa $H$, Matsuzaki M, Matsuzawa $Y$, Saito $Y$, Ishikawa $Y$, et al. Effects of eicosapentaenoic acid on major coronary events in hypercholesterolaemic patients (JELIS): a randomised open-label, blinded endpoint analysis. Lancet. 2007:369:1090-8.

38. Keech A, Simes RJ, Barter P, Best J, Scott R, Taskinen MR, et al. Effects of long-term fenofibrate therapy on cardiovascular events in 9795 people with type 2 diabetes mellitus (the FIELD study): randomised controlled trial. Lancet. 2005;366:1849-61.

39. Colhoun HM, Betteridge DJ, Durrington PN, Hitman GA, Neil HA, Livingstone SJ, et al. Primary prevention of cardiovascular disease with atorvastatin in type 2 diabetes in the Collaborative Atorvastatin Diabetes Study (CARDS): multicentre randomised placebo-controlled trial. Lancet. 2004:364:685-96. 
40. Sasaki S, Nakagawa M, Nakata T, Azuma A, Sawada S, Takeda K, et al. Effects of pravastatin on exercise electrocardiography test performance and cardiovascular mortality and morbidity in patients with hypercholesterolemia: lipid intervention study in Kyoto. Circ J. 2002;66:47-52.

41. Ballantyne CM, Olsson AG, CookTJ, Mercuri MF, Pedersen TR, Kjekshus J. Influence of low high-density lipoprotein cholesterol and elevated triglyceride on coronary heart disease events and response to simvastatin therapy in 4S. Circulation. 2001;104:3046-51.

42. Durrington PN, Bhatnagar D, Mackness MI, Morgan J, Julier K, Khan MA et al. An omega-3 polyunsaturated fatty acid concentrate administered for one year decreased triglycerides in simvastatin treated patients with coronary heart disease and persisting hypertriglyceridaemia. Heart. 2001:85:544-8.

43. Rubins HB, Robins SJ, Collins D, Fye CL, Anderson JW, Elam MB, et al. Gemfibrozil for the secondary prevention of coronary heart disease in men with low levels of high-density lipoprotein cholesterol. Veterans affairs high-density lipoprotein cholesterol intervention Trial Study Group. N Engl J Med. 1999;341:410-8.

44. Anthony AB, Deepak LB. Prevention of cardiovascular events and death with pravastatin in patients with coronary heart disease and a broad range of initial cholesterol levels. N Engl J Med. 1998;339:1349-57.

45. Sacks FM, Pfeffer MA, Moye LA, Rouleau JL, Rutherford JD, Cole TG, et al. The effect of pravastatin on coronary events after myocardial infarction in patients with average cholesterol levels. Cholesterol and Recurrent Events Trial investigators. N Engl J Med. 1996;335:1001-9.

46. Shepherd J, Cobbe SM, Ford I, Isles CG, Lorimer AR, MacFarlane PW, et al. Prevention of coronary heart disease with pravastatin in men with hypercholesterolemia. West of Scotland Coronary Prevention Study Group. N Engl J Med. 1995;333:1301-7.

47. Carlson LA, Rosenhamer G. Reduction of mortality in the Stockholm Ischaemic Heart Disease Secondary Prevention Study by combined treatment with clofibrate and nicotinic acid. Acta Med Scand. 1988;223:405-18.

48. Manninen V, Elo MO, Frick MH, Haapa K, Heinonen OP, Heinsalmi P, et al. Lipid alterations and decline in the incidence of coronary heart disease in the Helsinki Heart Study. JAMA. 1988;260:641-51.

49. Tani S, Matsumoto M, Nagao K, Hirayama A. Association of triglyceriderich lipoproteins-related markers and low-density lipoprotein heterogeneity with cardiovascular risk: effectiveness of polyacrylamide-gel electrophoresis as a method of determining low-density lipoprotein particle size. J Cardiol. 2014;63:60-8.

50. Francik R, Kryczyk J, Francik S. Coronary effect of fibrates on proteins and enzymes which hydrolyze triacylglycerols. Acta Pol Pharm. 2016;73:579-88
51. Pires da Rosa G, Libanio D, Filipe AL. Analysis of the Cochrane review: fibrates for secondary prevention of cardiovascular disease and stroke. Rev Port Cardiol. 2017;36:55-8.

52. Bhagavathula AS, Aldhaleei WA, Al Matrooshi NO, Rahmani J. Efficacy of statin/ezetimibe for secondary prevention of atherosclerotic cardiovascular disease in asian populations: a systematic review and meta-analysis of randomized controlled trials. Clin Drug Investig. 2020. https://doi. org/10.1007/s40261-020-00951-1.

53. Maki KC, Dicklin MR. Omega-3 fatty acid therapy for cardiovascular disease: justified or not? Curr Opin Cardiol. 2020;35:417-22.

54. Cederbaum Al. Role of lipid peroxidation and oxidative stress in alcohol toxicity. Free Radic Biol Med. 1989;7:537-9.

55. Estrela GR, Arruda AC, Torquato HFV, Freitas-Lima LC, Perilhao MS, Wasinski F, et al. Gemfibrozil induces anemia, leukopenia and reduces hematopoietic stem cells via PPAR-alpha in mice. Int J Mol Sci. 2020;21:5050.

56. Haim M, Benderly M, Boyko V, Goldenberg I, Tanne D, Battler A, et al. Decrease in triglyceride level by bezafibrate is related to reduction of recurrent coronary events: a Bezafibrate Infarction Prevention substudy. Coron Artery Dis. 2006;17:455-61.

57. Fruchart JC. Pemafibrate (K-877), a novel selective peroxisome proliferator-activated receptor alpha modulator for management of atherogenic dyslipidaemia. Cardiovasc Diabetol. 2017:16:124.

58. Fruchart JC, Santos RD. SPPARM alpha: the Lazarus effect. Curr Opin Lipidol. 2019;30:419-27.

59. Blair HA. Pemafibrate: first global approval. Drugs. 2017;77:1805-10.

60. Pradhan AD, Paynter NP, Everett BM, Glynn RJ, Amarenco P, Elam M, et al Rationale and design of the Pemafibrate to Reduce Cardiovascular Outcomes by Reducing Triglycerides in Patients with Diabetes (PROMINENT) study. Am Heart J. 2018;206:80-93.

61. Austin MA, McKnight B, Edwards KL, Bradley CM, McNeely MJ, Psaty BM, et al. Cardiovascular disease mortality in familial forms of hypertriglyceridemia: a 20-year prospective study. Circulation. 2000;101:2777-82.

\section{Publisher's Note}

Springer Nature remains neutral with regard to jurisdictional claims in published maps and institutional affiliations.
Ready to submit your research? Choose BMC and benefit from:

- fast, convenient online submission

- thorough peer review by experienced researchers in your field

- rapid publication on acceptance

- support for research data, including large and complex data types

- gold Open Access which fosters wider collaboration and increased citations

- maximum visibility for your research: over 100M website views per year

At BMC, research is always in progress.

Learn more biomedcentral.com/submissions 